\title{
Aminoglycoside resistance profile and structural architecture of the aminoglycoside acetyltransferase $\operatorname{AAC}\left(6^{\prime}\right)$-Im
}

\author{
Clyde A. Smith ${ }^{1, *}$, Monolekha Bhattacharya ${ }^{2}$, Marta Toth ${ }^{2}$, Nichole K. Stewart ${ }^{2}$ and Sergei B. Vakulenko ${ }^{2, *}$ \\ ${ }^{1}$ Stanford Synchrotron Radiation Lightsource, SLAC National Accelerator Laboratory, Menlo Park, CA 94025, USA. \\ ${ }^{2}$ Department of Chemistry and Biochemistry, University of Notre Dame, Notre Dame, IN 46556, USA. \\ * Corresponding Authors: \\ Clyde A. Smith, Stanford Synchrotron Radiation Lightsource, Stanford University, 2575 Sand Hill Rd, Menlo Park, CA 94025; \\ Phone: (650) 926-8544; Fax: (650) 926-3292; E-mail: csmith@slac.stanford.edu \\ Sergei Vakulenko, Department of Chemistry and Biochemistry, University of Notre Dame, 340D McCourtney Hall, Notre Dame, \\ IN, 46556; Phone: (574) 631-2935; Fax: (574) 631-6652; E-mail: svakulen@nd.edu
}

\begin{abstract}
Aminoglycoside 6' -acetyltransferase-Im (AAC(6')- $\mathrm{Im})$ is the closest monofunctional homolog of the $A A C\left(6^{\prime}\right)$-le acetyltransferase of the bifunctional enzyme AAC(6')-le/APH(2")-la. The AAC(6')-Im acetyltransferase confers 4- to 64-fold higher MICs to 4,6-disubstituted aminoglycosides and the 4,5-disubstituted aminoglycoside neomycin than $A A C\left(6^{\prime}\right)$-le, yet unlike $A A C\left(6^{\prime}\right)$-le, the $A A C\left(6^{\prime}\right)$-Im enzyme does not confer resistance to the atypical aminoglycoside fortimicin. The structure of the kanamycin $A$ complex of AAC $\left(6^{\prime}\right)$-Im shows that the substrate binds in a shallow positively-charged pocket, with the N6' amino group positioned appropriately for an efficient nucleophilic attack on an acetyl-CoA cofactor. The $A A C\left(6^{\prime}\right)$-le enzyme binds kanamycin $A$ in a sufficiently different manner to position the N6' group less efficiently, thereby reducing the activity of this enzyme towards the 4,6disubstituted aminoglycosides. Conversely, docking studies with fortimicin in both acetyltransferases suggest that the atypical aminoglycoside might bind less productively in $A A C\left(6^{\prime}\right)-I m$, thus explaining the lack of resistance to this molecule.
\end{abstract}

doi: 10.15698/mic2017.12.602

Received originally: 23.08.2017;

in revised form: 19.10.2017,

Accepted 19.10.2017,

Published 09.11.2017.

Keywords: antibiotic resistance, aminoglycosides, acetyltransferase, crystal structure.
Abbreviations:
$A A C\left(6^{\prime}\right)$-Im - Aminoglycoside 6'-
acetyltransferase-Im,
MIC - minimal inhibitory
concentration,
rmsd-root-mean-square-deviation.

\section{INTRODUCTION}

Aminoglycosides are potent, broad-spectrum bactericidal antibiotics used to treat many serious bacterial infections [1]. Among the three major structural groups of aminoglycosides, 4,6-disubstituted, 4,5-disubstituted, and atypical, the 4,6-disubstituted compounds are the most commonly used in the clinic (Figure S1). Aminoglycosides bind to the $30 \mathrm{~S}$ ribosomal subunit, resulting in mistranslation and ultimately, bacterial death [2-4]. The spread of bacterial strains resistant to aminoglycosides constitutes the major impediment for clinical use of this class of antibiotics. The major mechanism of aminoglycoside resistance in Gram-positive pathogens is the production of aminoglycoside-modifying enzymes, which include aminoglycoside acetyltransferases (AACs), aminoglycoside phosphotransferases (APHs), and aminoglycoside nucleotidyltransferases (ANTs) [5-8]. In Gram-negative bacteria, methylation of the ribosomal RNA provides an additional line of defense against aminoglycoside antibiotics [9].
The most important aminoglycoside-modifying enzyme in staphylococci and enterococci is the bifunctional $\operatorname{AAC}\left(6^{\prime}\right)-\mathrm{le} / \mathrm{APH}\left(2^{\prime \prime}\right)-\mathrm{la}$, due both to its wide dissemination in these pathogens, and to the wide spectrum of resistance which it confers. It is currently unclear as to what might be the advantage of having two different resistance elements on the same polypeptide in a bifunctional enzyme, as opposed to the expression of two independent monofunctional enzymes [10]. Possibilities include the coexpression of two disparate resistance activities to counteract the presence of a single antibiotic, or substrate channeling [11], although there is minimal evidence for the latter. The recent small-angle X-ray scattering (SAXS) study on the bifunctional AAC(6')-le/APH(2")-la enzyme suggests that the two active sites are on opposite sides of the enzyme which would preclude any channeling or cooperativity [12]. Although the bifunctional enzyme has been identified exclusively in Gram-positive bacteria to date, we recently char- 


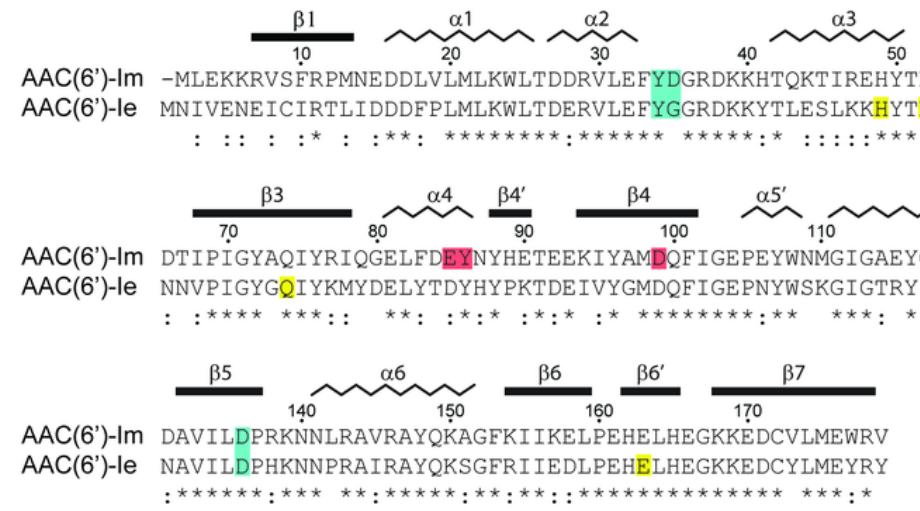

FIGURE 1: Sequence alignment of AAC(6')-Im and AAC(6')-le. The secondary structure assignment for $\operatorname{AAC}\left(6^{\prime}\right)$-Im is shown above, and the identity $\left({ }^{*}\right)$ and similarity (:) is indicated below each block of sequence. Amino acids involved in kanamycin A binding are shaded blue for those which are common to both enzymes, red for amino acids which interact with kanamycin A only in $\operatorname{AAC}\left(6^{\prime}\right)$ - Im, and yellow for amino acids which interact with kanamycin A only in $A A C\left(6^{\prime}\right)$-le [12]. The $A A C\left(6^{\prime}\right)$-Im enzyme is one residue shorter than $A A C\left(6^{\prime}\right)$-le, so for the sake of simplicity, the AAC $\left(6^{\prime}\right)$-Im sequence numbering begins at Met2 so that the sequence numbering is the same for both enzymes.

acterized the APH(2")-If phosphotransferase, the monofunctional counterpart of the phosphotransferase domain of $\operatorname{AAC}\left(6^{\prime}\right)-\mathrm{le} / \mathrm{APH}\left(2^{\prime \prime}\right)-\mathrm{la}$, which was found in the Gramnegative pathogen Campylobacter jejuni [13]. The monofunctional counterpart $\left(\mathrm{AAC}\left(6^{\prime}\right)-\mathrm{Im}\right)$ of the acetyltransferase domain of the bifunctional enzyme has been identified in both Gram-negative and Gram-positive clinical isolates [14]. It shares $60 \%$ sequence identity and $83 \%$ similarity with $\mathrm{AAC}\left(6^{\prime}\right)$-le (Figure 1).

The $A A C\left(6^{\prime}\right)-I$ enzymes can be divided into three subfamilies, based upon their structural and kinetic properties $[15,16]$. The $A A C\left(6^{\prime}\right)$-le and $A A C\left(6^{\prime}\right)$-lb enzymes are classified together in sub-family $C$, whose members are all monomeric enzymes. The $A A C\left(6^{\prime}\right)-\operatorname{Ig}, A A C\left(6^{\prime}\right)-$ Ih and $A A C\left(6^{\prime}\right)$-Iy enzymes are in sub-family $A$ and are domain-swapped dimers, with the $C$-terminal $\beta$-strand from one protein chain inserted between two strands from the neighboring molecule. The close proximity of the two protein chains in the dimer brings each monomer close enough such that a loop from one monomer forms part of the other chain's active site, and vice versa [16]. The $A A C\left(6^{\prime}\right)$-li enzyme is currently the sole member of sub-family $B$, and although this enzyme is also dimeric, the oligomer formed is different from the sub-

family A dimer. Moreover the AAC $\left(6^{\prime}\right)$-li enzyme acetylates only aminoglycosides, similar to that of the monomeric sub-family $C$ enzymes, whereas the sub-family $A$ enzymes have been shown to acetylate both aminoglycoside and non-aminoglycoside substrates [16].

The high resolution crystal structure of the kanamycin $A$ complex of $A A C\left(6^{\prime}\right)$-le has been reported [12]. Given the strong familial relationship between $\operatorname{AAC}\left(6^{\prime}\right)-\mathrm{Im}$ and $A A C\left(6^{\prime}\right)$-le, we have undertaken the enzymological and structural analyses of these enzymes. Here we report the antibiotic susceptibility and kinetic profile and the X-ray structure of the $\operatorname{AAC}\left(6^{\prime}\right)$-Im acetyltransferase in its apo form and as the binary kanamycin A complex, and classify the enzyme as a member of the $A A C\left(6^{\prime}\right)-I$ sub-family $C$. An analysis of the structural features involved in substrate binding provides insight into the modulation of the activity of these enzymes.

\section{RESULTS AND DISCUSSION \\ Antibiotic resistance profile}

When expressed in the Escherichia coli JM83 strain, $\operatorname{AAC}\left(6^{\prime}\right)$-Im produces resistance to a wide range of clinically important 4,6-disubstituted aminoglycosides with minimal inhibitory concentration (MIC) values 8 - 128-fold above those for the recipient strain (Table 1). The enzyme increases MICs of the 4,5-disubstituted antibiotic neomycin 8 -fold, while the MICs of paromomycin and lividomycin remain at background level. No significant change in MIC values is observed for the atypical aminoglycosides hygromycin (2-fold) and fortimicin (no change). When compared to its closely-related counterpart, $\operatorname{AAC}\left(6^{\prime}\right)$-le, from the bifunctional $A A C\left(6^{\prime}\right)-l e / A P H\left(2^{\prime \prime}\right)$-la enzyme, the monofunctional $A A C\left(6^{\prime}\right)$-Im acetyltransferase overall produces significantly higher (4 - 64-fold) levels of resistance to the 4,6disubstituted aminoglycosides (Table 1 ). In stark contrast, while $\operatorname{AAC}\left(6^{\prime}\right)$-Im fails to elevate resistance to the atypical aminoglycoside, fortimicin, $A A C\left(6^{\prime}\right)$-le produces a significant (32-fold) increase in the MIC of this antibiotic.

\section{Kinetic studies}

To evaluate whether differences in MICs produced by the $A A C\left(6^{\prime}\right)-I m$ and $A A C\left(6^{\prime}\right)$-le acetyltransferases result from differences in the turnover rates or apparent affinity of substrates for these enzymes, we attempted to determine the steady-state kinetic parameters $k_{\text {cat }}$ and $K_{\mathrm{m}}$ for $\mathrm{AAC}\left(6^{\prime}\right)$ Im and compare them to those previously reported for AAC $\left(6^{\prime}\right)$-le [17]. However, we observed strong substrate inhibition with all 4,6-disubstituted aminoglycosides at concentrations required to determine $k_{\text {cat }}$ and $K_{\mathrm{m}}$ values, which prevents their determination. It should be noted that substrate inhibition was also observed for many aminoglycosides with AAC $\left(6^{\prime}\right)$-le [17], however it was less significant, allowing for the determination of these parameters. 
TABLE 1. MIC profile of aminoglycosides for E. coli JM83 expressing $A A C\left(6^{\prime}\right)-I m$ and $A A C\left(6^{\prime}\right)$-le.

\begin{tabular}{|c|c|c|c|}
\hline \multirow{2}{*}{ Aminoglycoside } & \multicolumn{3}{|l|}{$\mathrm{MIC}(\mu \mathrm{g} / \mathrm{ml})$} \\
\hline & $A A C\left(6^{\prime}\right)-I m$ & $\operatorname{AAC}\left(6^{\prime}\right)-\mathrm{le}$ & E. coli JM83 \\
\hline \multicolumn{4}{|l|}{ 4,6-Disubstituted } \\
\hline Tobramycin & 64 & 4 & 0.5 \\
\hline Amikacin & 64 & 4 & 0.5 \\
\hline Kanamycin A & 256 & 64 & 4 \\
\hline Kanamycin B & 128 & 16 & 1 \\
\hline Isepamicin & 32 & 4 & 2 \\
\hline Dibekacin & 64 & 2 & 0.5 \\
\hline Netilmicin & 32 & 0.5 & 0.5 \\
\hline Sisomicin & 16 & 1 & 0.5 \\
\hline Arbekacin & 4 & 1 & 0.5 \\
\hline \multicolumn{4}{|l|}{ 4,5-Disubstituted } \\
\hline Neomycin & 4 & 1 & 0.5 \\
\hline Paromomycin $^{a}$ & 8 & 8 & 8 \\
\hline Lividomycin $^{a}$ & 8 & 8 & 8 \\
\hline \multicolumn{4}{|l|}{ Atypical } \\
\hline Hygromycin & 64 & 64 & 32 \\
\hline Fortimicin & 2 & 64 & 2 \\
\hline
\end{tabular}

${ }^{a}$ These aminoglycosides have a hydroxyl at the $6^{\prime}$ position and thus are not substrates for the $A A C\left(6^{\prime}\right)$ enzymes.

As we were unable to evaluate $k_{\text {cat, }}$ and $K_{\mathrm{m}}$ values for the majority of aminoglycosides used in our study, we chose to measure the rate constant for acetylation at a single concentration of each substrate (Figure 2). This was done at $5 \mu \mathrm{M}$ of aminoglycoside to minimize the effect of substrate inhibition. For most aminoglycosides we observed relatively good correlation between the acetylation rate constants and the MIC values (Figure 2 and Table 1). The exception to this was neomycin for which the low resistance level conferred $(4 \mu \mathrm{g} / \mathrm{ml})$ does not match the relatively high acetylation rate $\left(0.95 \mathrm{~s}^{-1}\right)$. For neomycin, it has been reported that the acetylated antibiotic still retains significant antimicrobial activity [18-21], which may explain the low MIC observed for this antibiotic with $A A C\left(6^{\prime}\right)-\mathrm{Im}$.

\section{Kanamycin A binding by $A A C\left(6^{\prime}\right)$-Im}

The $A A C\left(6^{\prime}\right)$-Im structure was solved in both the apo-form at $1.7 \AA$ resolution, and as the binary complex with kanamycin A $\left(\mathrm{AAC}\left(6^{\prime}\right)\right.$-Im-kanamycin A) to $1.95 \AA$ resolution (Table S1). The overall structure is shown in Figure 3A. The kanamycin binding site is in a shallow highly negativelycharged pocket in the molecular surface (Figure 3B). Strands $\beta 3, \beta 4$ and $\beta 5$ form the base of the pocket, with helices $\alpha 2, \alpha 3$ and $\alpha 4$, strand $\beta 6^{\prime}$, and the loop between helix $\alpha 3$ and strand $\beta 2$ forming the walls (Figure $3 A$ ). The kanamycin $A$ molecule is anchored by twelve hydrogen bonds, four to the $A$ ring, five to the central $B$ ring, and three to the $\mathrm{C}$ ring (Figure $3 \mathrm{C}$ and Table $\mathrm{S2}$ ). The $\mathrm{A}$ ring is further stabilized by a hydrophobic face-to-face packing interaction with the side chain of Tyr34 (Figure 3C) which serves to help orient the ring such that the $\mathrm{N}^{\prime}$ side group is positioned correctly for acetylation. At the opposite end of the substrate, the $C$ ring is also held in position by a face-to-face hydrophobic interaction with the side chain of Trp54 from the $\alpha 3-\beta 2$ loop (Figure $3 C$ ). Superposition of the apo-AAC $\left(6^{\prime}\right)-\mathrm{Im}$ and $\mathrm{AAC}\left(6^{\prime}\right)-\mathrm{Im}$-kanamycin $\mathrm{A}$ structures gives an root-mean-square deviation ( $r m s d)$ of $0.6 \AA$. Inspection of the superimposed structures shows that although there are no major differences in the overall structure of the enzyme upon substrate binding, there are some minor rearrangements of the residues inside the kanamycin binding site. A $\beta$-hairpin formed by strand $\beta 6^{\prime}$ and the $\mathrm{N}$-terminal end of strand $\beta 7$ moves inward as a rigid body (Figure S2). Although there is no direct contact between residues in this strand-loop-strand motif and kanamycin, there is a water-mediated contact with His165 and the O4' atom of the substrate (Figure S2). In addition, small inward or outward movements of side chains which surround the kanamycin molecule are also observed (Figure S2), primarily to facilitate efficient hydrogen bonding and hydrophobic interactions with the substrate.

Superposition of $A A C\left(6^{\prime}\right)$-Im onto the six other $A A C\left(6^{\prime}\right)$ enzymes whose structures have been reported gave $r m s d s$ of $1.0 \AA$, $1.7 \AA$, $2.4 \AA, 2.7 \AA$, $3.0 \AA$, and $2.9 \AA$ for $A A C\left(6^{\prime}\right)$-le [12], $\operatorname{AAC}\left(6^{\prime}\right)$-Ib [22, 23], AAC(6 $\left.6^{\prime}\right)$-li [24], $A A C\left(6^{\prime}\right)$-lg [16], $A A C\left(6^{\prime}\right)$-Ih [16], and $A A C\left(6^{\prime}\right)$-ly [25], respectively (Table S3). The variation in the rmsds is consistent with the familial relationships between these enzymes. A number of these enzyme structures were solved as complexes with aminoglycoside substrates; the coenzyme-A (CoA) and kanamycin A complex of AAC $\left(6^{\prime}\right)-\mathrm{lb}\left(\mathrm{AAC}\left(6^{\prime}\right)\right.$-lb-CoA-kanamycin A; PDB code $2 Q I R)$, the $A A C\left(6^{\prime}\right)$-lb-acetyl-CoA-kanamycin $C$ complex (PDB code $1 \mathrm{VOC}$ ), the $\mathrm{AAC}\left(6^{\prime}\right)$-lb-CoA-ribostamycin complex (PDB code 2BUE), the AAC(6 $\left.6^{\prime}\right)$-lb-acetyl-CoAparomomycin complex (PDB code 2VQY), the AAC $\left(6^{\prime}\right)$-leCoA-kanamycin A complex (PDB code 4QC6), the AAC(6')Ig-tobramycin complex (PDB code 4EVY), and the $A A C\left(6^{\prime}\right)$ ly-CoA-ribostamycin complex (PDB code 1S3Z).

\section{Structural comparison of $A A C\left(6^{\prime}\right)$-Im with $A A C\left(6^{\prime}\right)$-le}

To gain some structural insights into the differences in MICs between the closely related enzymes $A A C\left(6^{\prime}\right)$-Im and

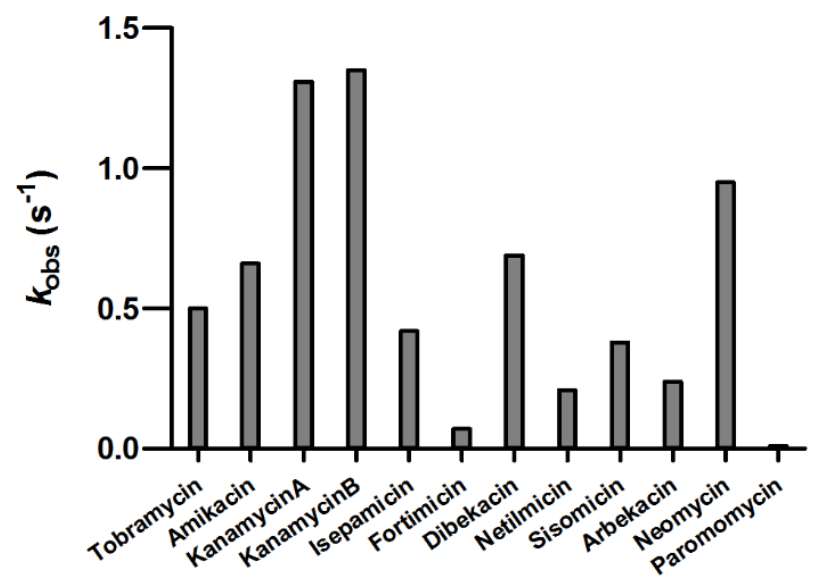

FIGURE 2: The rate constants for the acetyltransferase activity of AAC (6')-Im for selected aminoglycosides. 

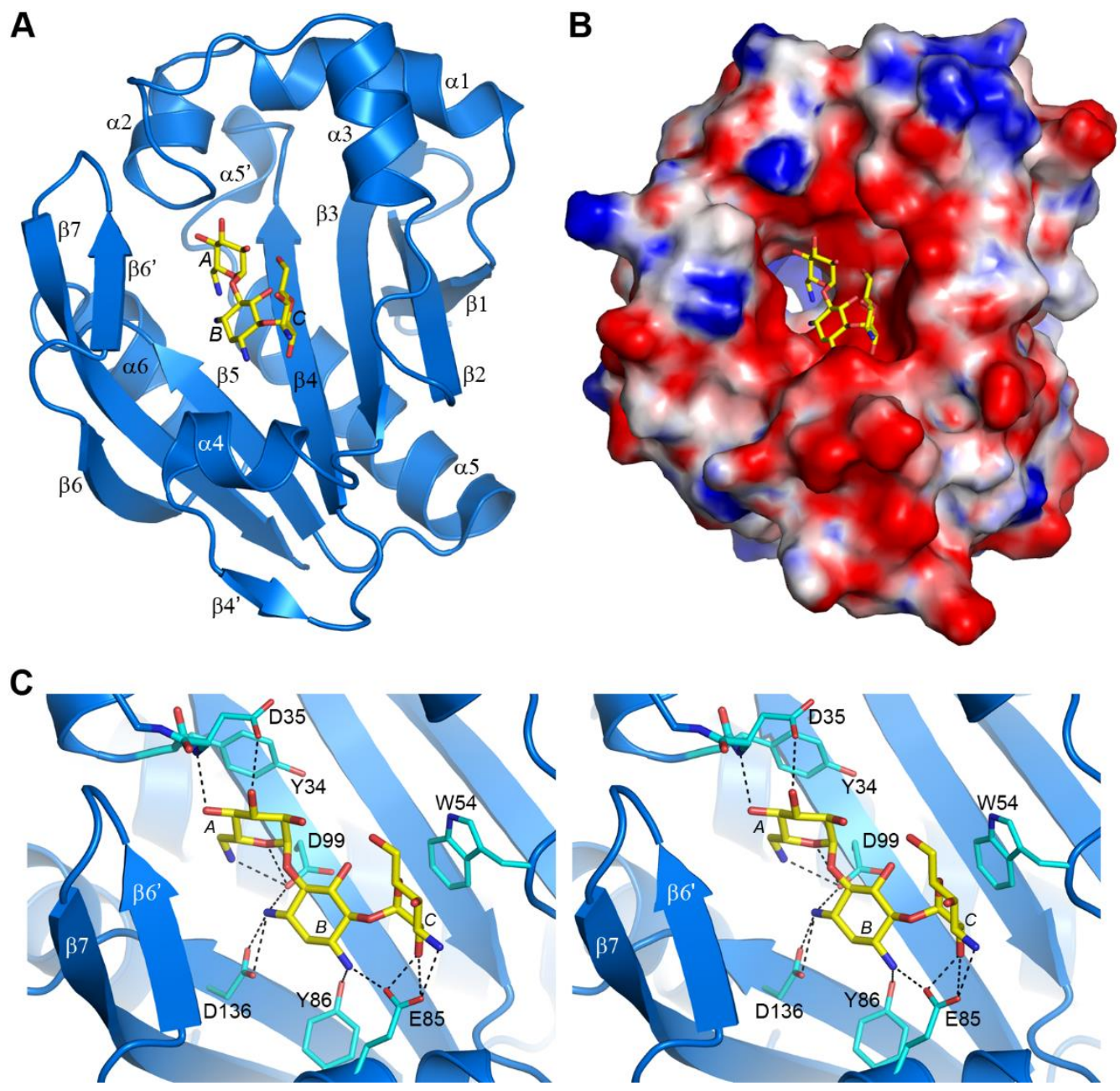

FIGURE 3: The kanamycin A complex of $A A C\left(6^{\prime}\right)-I m$. (A) Ribbon representation of $A A C\left(6^{\prime}\right)$-Im (blue) with the bound kanamycin $A$ shown as yellow sticks. The secondary structure nomenclature used throughout the paper is indicated. (B) Electrostatic surface representation of $\mathrm{AAC}\left(6^{\prime}\right)-\mathrm{Im}$, with the surface potentials ranging from $-5 \mathrm{kT} / \mathrm{e}$ (red) to $+5 \mathrm{kT} / \mathrm{e}$ (blue). The bound kanamycin $A$ is shown as yellow sticks. (C) Stereoview of the kanamycin A binding site of $A A C\left(6^{\prime}\right)$ - $I m$, showing the hydrogen bonding interactions (black dashed lines) of kanamycin A (yellow sticks) with the protein side chains (cyan sticks).

AAC $\left(6^{\prime}\right)$-le from sub-family $C$, the kanamycin A complexes of these enzymes were analyzed in detail. In $\operatorname{AAC}\left(6^{\prime}\right)$-le, the kanamycin $A$ substrate is anchored by ten hydrogen bonds to the protein (four with the A ring, one with the central $B$ ring and five with the $C$ ring), along with a number of water molecules (Figure S3) [12]. The hydrogen bonding network differs substantially from that described for $A A C\left(6^{\prime}\right)$-Im (Figure $3 \mathrm{C}$ and Table $\mathrm{S} 2$ ), in particular at the $\mathrm{B}$ ring which in $A A C\left(6^{\prime}\right)$-le is anchored by a single hydrogen bond compared to five in $A A C\left(6^{\prime}\right)-\mathrm{Im}$. Although the number of hydrogen bonds with the $A$ ring is similar in both enzymes, the residues involved differ. These changes in the hydrogen bonding patterns could contribute to the differences in the observed MICs for the two enzymes.

Despite the fact that there are only two sequence differences between the two enzymes in the vicinity of the binding site (Asp35 and Glu85 in AAC(6')-Im are glycine and aspartate, respectively, in $\mathrm{AAC}\left(6^{\prime}\right)$-le (Figure 1)), there is a significant shift in the orientation of the substrate in these two enzymes (Figure 4A). When the kanamycin A conformations are compared it can be seen that in $A A C\left(6^{\prime}\right)-1 \mathrm{~m}$, the A ring (containing the $N 6^{\prime}$ site of modification) is rotated approximately $45^{\circ}$ relative to the $A$ ring position in $A A C\left(6^{\prime}\right)$-le. This, in turn, moves the $B$ and $C$ rings in AAC (6')-Im towards helix $\alpha 4$, Asp136 and Glu85 (Figure 4A). This movement, which results in a difference of approximately $4.5 \AA$ in the positions of the $C$ rings in the two enzyme complexes, is primarily facilitated by a change in conformation of the loop between helix $\alpha 3$ and strand $\beta 2$, and structural and sequence differences in the $\alpha 4$ helix (Figure $4 B)$. The presence of a conformationally-restricted proline (Pro53) at the C-terminus of helix $\alpha 3$ in AAC $\left(6^{\prime}\right)$-le leads to an alteration of the main chain dihedral $\psi$ angle at this residue (Figure $4 \mathrm{C}$ ). Prolines typically have their main chain dihedral angle $\phi$ constrained to near $-60^{\circ}$, with the $\psi$ angle adopting either $-45^{\circ}$ or $135^{\circ}$. The Pro53 residue in $\operatorname{AAC}\left(6^{\prime}\right)$ le has $\phi$ and $\psi$ angles of $-75^{\circ}$ and $158^{\circ}$, respectively, such that the carbonyl oxygen points into the substrate binding 

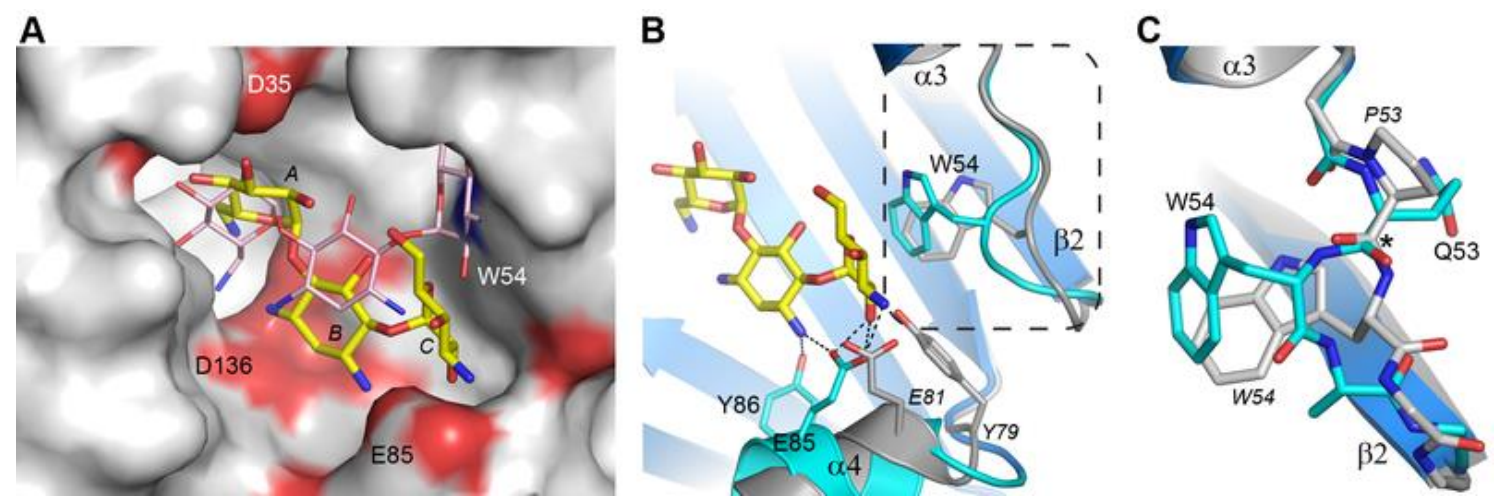

FIGURE 4: Structural comparison of $A A C\left(6^{\prime}\right)-I m$ and $A A C\left(6^{\prime}\right)$-le. (A) Molecular surface representation of the binding site of $A A C\left(6^{\prime}\right)-\operatorname{Im}$ (grey, red and blue shading). The kanamycin A molecule in $A A C\left(6^{\prime}\right)$-Im binding site is shown as yellow sticks and the kanamycin A molecule in $\mathrm{AAC}\left(6^{\prime}\right)$-le is shown as thin pink sticks. (B) Ribbon representation of the loop between helix $\alpha 3$ and strand $\beta 2$ shown in cyan for $A A C\left(6^{\prime}\right)-\operatorname{Im}$ and grey for $A A C\left(6^{\prime}\right)$-le. The location of the Trp54 side chain is indicated for both enzymes. The kanamycin A molecule in $\operatorname{AAC}\left(6^{\prime}\right)$ - $\operatorname{Im}$ is shown as yellow sticks. The dashed box shows the area represented in panel $C$. (C) Close up view of the conformational difference caused by the presence of Pro53 in AAC (6')-le (grey) relative to a $\mathrm{Gln} 53$ in AAC (6')-Im (cyan). The difference in orientation of the residue 53 carbonyl group is indicated by the asterisk. Residues from $\operatorname{AAC}\left(6^{\prime \prime}\right)$-le are labeled in italics.

site and the main chain which follows, projects outward (Figure 4C). Consequently, the side chain of Trp54 in AAC $\left(6^{\prime}\right)$-le moves approximately 3 - 4 A away from the substrate binding site (Figures $4 B$ and $4 C$ ) and the $C$ ring of kanamycin $A$ moves to maintain the hydrophobic interaction. Moreover, sequence differences at the $\mathrm{N}$-terminus of helix $\alpha 4$ in $A A C\left(6^{\prime}\right)$-le result in two bulky residues (Tyr79 and Glu81) projecting into the binding site, further preventing the $C$ and $B$ rings from adopting the conformation observed in $A A C\left(6^{\prime}\right)$-Im (Figures $4 A$ and $4 B$ ).

In the $A A C\left(6^{\prime}\right)$-Im enzyme, the equivalent residue at position 53 on the $\alpha 3-\beta 2$ loop is a glutamine $\left(\phi / \psi\right.$ angles, $-98^{\circ}$ and $72^{\circ}$ ), with its carbonyl oxygen pointing outward and the Trp54 side chain projecting inward (Figure 4C). In this orientation it would severely clash with the $\mathrm{C}$ ring of kanamycin were the substrate to bind in the same manner as observed in $A A C\left(6^{\prime}\right)$-le (Figure $\left.4 A\right)$. The $C$ ring, therefore, must adopt a position away from the tryptophan, moving towards helix $\alpha 4$ where it interacts with residue Glu85 at the C-terminal end of the helix (Figures $3 \mathrm{C}$ and $4 \mathrm{~B}$ ). Differences in sequence and structure at the $\mathrm{N}$-terminal end of helix $\alpha 4$ allow this part of the binding site to be more open than in $A A C\left(6^{\prime}\right)$-le and readily able to accommodate the movement of the substrate.

\section{Structural comparison of $A A C\left(6^{\prime}\right)-$ Im with other $A A C\left(6^{\prime}\right)$ enzymes}

To perform structural comparison of various aminoglycoside $6^{\prime}$ acetyltransferases, the structure the kanamycin $A$ complex of $A A C\left(6^{\prime}\right)-I m$ was superimposed onto the ribostamycin and paromomycin complexes of $A A C\left(6^{\prime}\right)-\mathrm{lb}$ (Figures S4A and S4B, respectively), the tobramycin complex of $A A C\left(6^{\prime}\right)$-Ig (Figure $S 4 C$ ) and the ribostamycin complex of $A A C\left(6^{\prime}\right)$-ly (Figure S4D). It should be noted that paromomycin has an oxygen atom at the $6^{\prime}$ position on the A ring (Figure S1), and thus is not a substrate for these enzymes. There are significant differences in the structure of the substrate binding site in $A A C\left(6^{\prime}\right)-\mathrm{lb}$ (relative to $A A C\left(6^{\prime}\right)$ $\mathrm{Im})$, and these are highlighted in Figure $\mathrm{S} 4 \mathrm{~A}$. The four main regions of structural variation are: (i) the loop between helix $\alpha 3$ and strand $\beta 2$ in $A A C\left(6^{\prime}\right)-I m$ is replaced by an $\alpha$ helix in $A A C\left(6^{\prime}\right)-1 b$; (ii) the $\alpha 2-\alpha 3$ loop is lengthened by a turn of $3_{10}$ helix; (iii) the absence of the strand equivalent to $\beta 6^{\prime}$ and the shortening of strand $\beta 7$; and (iv) the replacement of helix $\alpha 4$ and strand $\beta 4^{\prime}$ by an unstructured loop which projects into the binding site. However, despite these changes, the $A$ and $B$ rings of the 4,5-disubstituted aminoglycosides ribostamycin (Figure S4A) and paromomycin (Figure S4B) in $A A C\left(6^{\prime}\right)$-lb overlap almost exactly with the equivalent rings of kanamycin $A$ in $A A C\left(6^{\prime}\right)-\mathrm{Im}$. In both cases, the ribose moiety attached at the 5 position deviates markedly, projecting away from the kanamycin $A$ substrate $C$ ring position observed in $\operatorname{AAC}\left(6^{\prime}\right)-\mathrm{Im}$, towards the C-terminus of helix $\alpha 3$.

In the more distantly-related domain-swapped dimeric enzymes from sub-family $A$ of the $A A C\left(6^{\prime}\right)-I$ enzymes, $\operatorname{AAC}\left(6^{\prime}\right)$-Ig and $A A C\left(6^{\prime}\right)$-ly, the binding sites differ substantially. These two enzymes share $40 \%$ sequence identity with each other and are structurally very similar (Table S3), yet only show between $10-16 \%$ identity with $A A C\left(\sigma^{\prime}\right)-\operatorname{Im}$, $\operatorname{AAC}\left(6^{\prime}\right)$-le and $A A C\left(6^{\prime}\right)$-lb. In both $A A C\left(6^{\prime}\right)$-Ig and $A A C\left(6^{\prime}\right)$-ly, the $\beta 6^{\prime}-\beta 7$ hairpin is absent and the helix equivalent to helix $\alpha 3$ in $A A C\left(6^{\prime}\right)$-Im is one turn longer. This positions the loop, which is topologically equivalent to the $\alpha 3-\beta 2$ loop in $\mathrm{AAC}\left(6^{\prime}\right)-\mathrm{Im}$, approximately $4 \AA$ further from the binding pocket (Figures S4C and S4D). Similar to $\operatorname{AAC}\left(6^{\prime}\right)-\mathrm{lb}$, the equivalent of helix $\alpha 4$ is also missing from both $A A C\left(6^{\prime}\right)$-Ig and $A A C\left(6^{\prime}\right)-1 y$, and is replaced by an extended loop which in these enzymes has moved approximately $3-4 \AA$ away from the binding site. Moreover, a loop from the adjacent protein chain of the dimer inserts into the active site, and residues from this loop interact with the tobramycin and ribostamycin in these complexes. These combined structural differences make the substrate binding site in 

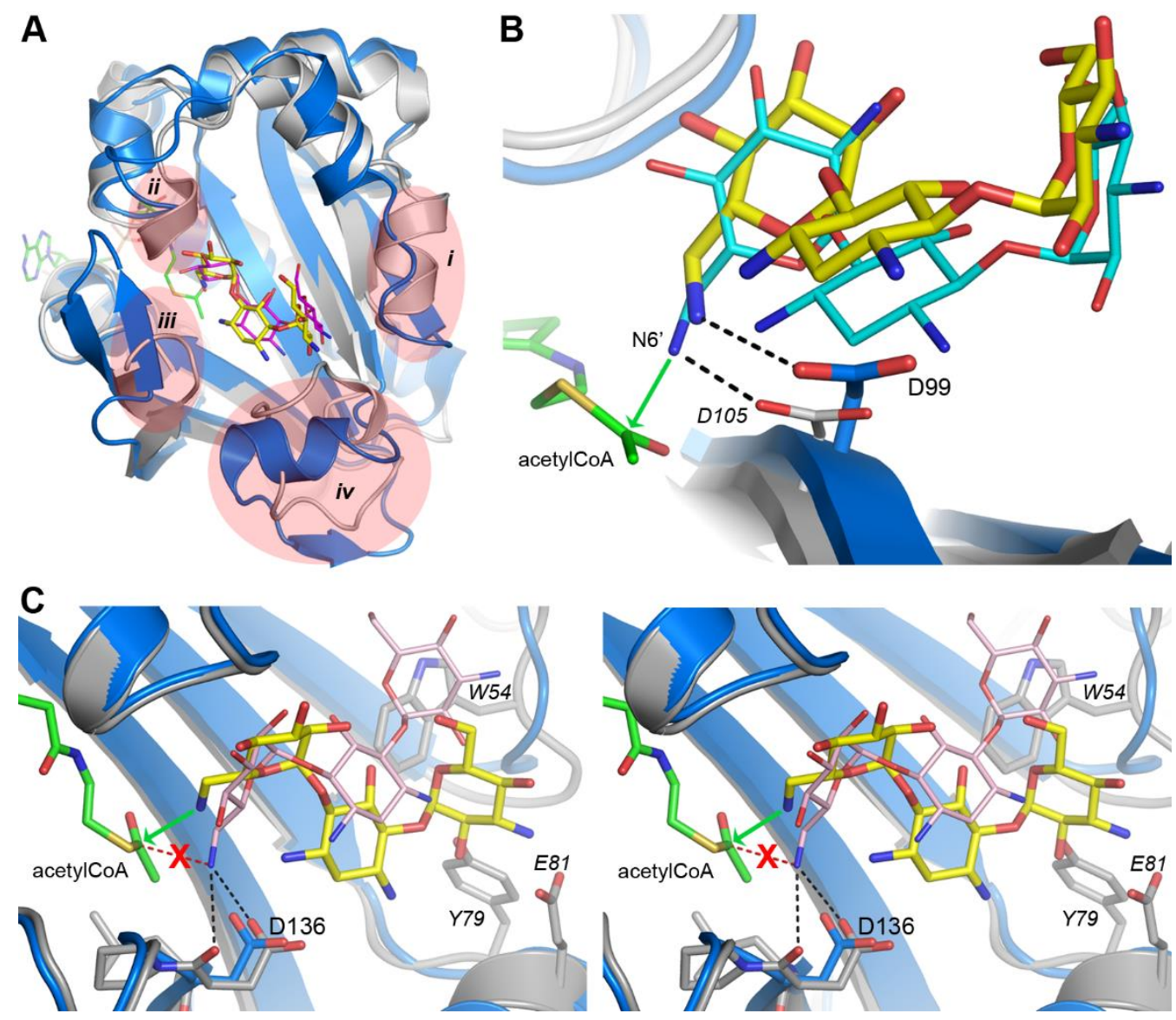

FIGURE 5: Structural comparison of $A A C\left(6^{\prime}\right)-\operatorname{Im}$ and $A A C\left(6^{\prime}\right)-1 b$. (A) Superposition of $A A C\left(6^{\prime}\right)$-Im (blue) and $A A C\left(6^{\prime}\right)-I b$ (grey). Kanamycin A is shown in yellow sticks for $A A C\left(6^{\prime}\right)-\mathrm{Im}$ and kanamycin $C$ in magenta sticks for $A A C\left(6^{\prime}\right)-1 \mathrm{~b}$. The acetyl-CoA cofactor present in $A A C\left(6^{\prime}\right)-1 \mathrm{~b}$ is shown as green sticks. The four main regions of structural difference near the substrate binding site are indicated in pale red, as described in Figure S4A. (B) Close up view of superimposed kanamycin A substrates in $A A C\left(6^{\prime}\right)$-Im (yellow with the enzyme shown in blue) and $A A C\left(6^{\prime}\right)-1 b$ (cyan with the enzyme shown in grey). In $A A C\left(6^{\prime}\right)$-lb the $N 6^{\prime}$ group is positioned by a hydrogen bond to the Asp105 side chain (labeled in italics), and the favorable close approach of the $\mathrm{NG}^{\prime}$ to the acetyl carbon is shown by the green arrow. A similar hydrogen bonding interaction is seen in $A A C\left(6^{\prime}\right)$-Im with the Asp99 side chain. (C) Stereoview close up of the active site in AAC $\left(6^{\prime}\right)$-le (grey) superimposed onto $\operatorname{AAC}\left(6^{\prime}\right)-\operatorname{Im}$ (blue). The kanamycin A substrates in $\operatorname{AAC}\left(6^{\prime}\right)$-Im (yellow) and $\operatorname{AAC}\left(6^{\prime}\right)$-le (pink) are shown. The difference in orientation of the two aminoglycosides directs the $\mathrm{N}^{\prime}$ group in $\mathrm{AAC}\left(6^{\prime}\right)$-le away from the acetyl-CoA, where it is anchored by two hydrogen bonds to Asp136. The favorable approach of the $N 6^{\prime}$ group to the acetyl carbon in the $A A C\left(6^{\prime}\right)$-Im-bound kanamycin $A$ is indicated by the green arrow, and what would be a unfavored orientation in $A A C\left(6^{\prime}\right)$-le is indicated by a red dashed line. Residues from $A A C\left(6^{\prime \prime}\right)$-le are labeled in italics.

the $A A C\left(6^{\prime}\right)$-Ig and $A A C\left(6^{\prime}\right)$-ly significantly larger [16] and consequently, the tobramycin and ribostamycin in these two enzymes bind in a completely different manner.

\section{Acetylation of aminoglycosides by $\operatorname{AAC}\left(6^{\prime}\right)$ enzymes}

The $\operatorname{AAC}\left(6^{\prime}\right)$-Im-kanamycin A complex was superimposed onto the kanamycin $A$ and kanamycin $C$ complexes of AAC $\left(6^{\prime}\right)-\mathrm{Ib}$ (PDB codes 2QIR and 1VOC, respectively). The antibiotic molecules occupy essentially the same position and have the same relative conformation in these enzymes (Figure $5 \mathrm{~A}$ ), despite the fact that there are some significant structural differences in the $A A C\left(6^{\prime}\right)-1 b$ substrate binding site (Figures S4A and $5 A$ ). The crystal structure of $A A C\left(6^{\prime}\right)$ Ib with acetyl-CoA and kanamycin C (PDB code 1VOC) provides valuable insight into the mechanism of acetylation in these enzymes. Although kanamycin $C$ is a variant of the antibiotic that has a hydroxyl group at the $6^{\prime}$ position and is therefore not a substrate for the $A A C\left(6^{\prime}\right)$ enzymes, it binds to $A A C\left(6^{\prime}\right)-I b$ in the presence of acetyl-CoA to give rise to an abortive ternary complex. In this structure, the $06^{\prime}$ atom is approximately $2.2 \AA$ from the carbon atom of the acetyl moiety, positioned to make an efficient nucleophilic attack were it an amide group [22]. After superposition, the kanamycin $A$ substrate in the $A A C\left(6^{\prime}\right)-1 b-C o A-$ kanamycin A complex (PDB code 2QIR) is in almost exactly the same place as the kanamycin $C$ molecule, such that the N6' atom would be approximately $2.0 \AA$ from the acetyl carbon, poised perfectly for attack (the position of the acetyl-CoA from the abortive AAC(6')-Ib-acetyl-CoA-kanamycin $C$ complex was also used for this comparison).

The position of the acetyl-CoA in the context of the $A A C\left(6^{\prime}\right)-I m$ structure is currently unknown, therefore the acetyl-CoA from the abortive $A A C\left(6^{\prime}\right)$-lb-acetyl-CoAkanamycin $C$ complex was used to represent the approximate location of the cofactor in $A A C\left(6^{\prime}\right)-I m$, giving rise to a composite model of an $\mathrm{AAC}\left(6^{\prime}\right)$-Im-acetyl-CoA-kanamycin $A$ 
complex. In this composite model, the distance between the $N 6^{\prime}$ group of the kanamycin $A$ in $A A C\left(6^{\prime}\right)$ - Im and the acetyl carbon is approximately $2.8 \AA$. A hydrogen bond between the $N 6^{\prime}$ atom and the side chain of a conserved aspartate (Asp99 in AAC(6')-Im (Figure 3C) and Asp105 in $\left.A A C\left(6^{\prime}\right)-I b\right)$ serves to orient the nucleophilic nitrogen atom so that it would be correctly positioned for direct transfer of the acetyl group to the kanamycin molecule (Figure 5B) in both of these enzymes.

When the kanamycin $A$ complex of $A A C\left(6^{\prime}\right)$-le is superimposed onto $A A C\left(6^{\prime}\right)-I m$, the rotation of the $A$ ring (described above) places the $N 6^{\prime}$ atom over $2 \AA$ from the equivalent position in $A A C\left(6^{\prime}\right)-I m$, anchored by two hydrogen bonds to the carbonyl oxygen and the side chain of Asp136 (Figures 5C and S3). More importantly, the nitrogen atom is directed away from the acetyl-CoA, approximately $3.1 \AA$ from the acetyl carbon, and in an orientation which would not favor an efficient interaction with the cofactor. The hydrogen bonding interaction with the Asp99 side chain, which serves to correctly orient the $N 6^{\prime}$ group in $A A C\left(6^{\prime}\right)-1 m$, is missing in $A A C\left(6^{\prime}\right)$-le. This difference in orientation of kanamycin in AAC $\left(6^{\prime}\right)$-le could explain the almost universally lower MIC's for the majority of the 4,6disubstituted aminoglycosides. Since the 4,6-disubstituted aminoglycosides all have essentially similar structures, it seems highly likely that the relocation of the Trp54 side chain and the insertion of the bulky residues Tyr79 and Glu81 at the N-terminus of helix $\alpha 4$ in $A A C\left(6^{\prime}\right)$-le (Figure $4 B$ ) could facilitate a rotation of these substrates similar to that seen for kanamycin. In order for the $\mathrm{N}^{\prime}$ atom of these 4,6-disubstituted aminoglycosides to be positioned for effective nucleophilic attack on the acetyl carbon, the hydrogen bonds holding the $\mathrm{NG}^{\prime}$ atom in the unproductive orientation would need to be broken so that the $\mathrm{C5}^{\prime}-\mathrm{C6}^{\prime}$ bond could rotate and allow the nitrogen to approach the acetyl carbon. This energy requirement could therefore give rise to the apparently lower activity of the $A A C\left(6^{\prime}\right)$-le enzyme.

These structural analyses of the kanamycin A complexes of $A A C\left(6^{\prime}\right)$-Im and $A A C\left(6^{\prime}\right)$-le show that conformational rearrangements within the substrate binding sites of these enzymes play key roles in the orientation of the bound kanamycin molecule. These structural changes alter the way in which the 4,6-disubstituted aminoglycosides are positioned in the binding site, affecting the orientation of the $\mathrm{NG}^{\prime}$ amino group relative to the acetyl donor, which could be responsible for differences in the activity of the enzymes. Given the high degree of sequence identity between the $A A C\left(6^{\prime}\right)$-Im and $A A C\left(6^{\prime}\right)$-le acetyltransferases, an evolutionary relationship between these two enzymes is highly likely, with both enzymes probably having diverged from a common ancestral precursor. The significantly lower MICs towards the 4,6-disubstituted aminoglycosides observed for the $A A C\left(6^{\prime}\right)$-le domain of the bifunctional enzyme (compared to the monofunctional $A A C\left(6^{\prime}\right)-I m$ ) suggest that any evolutionary pressure, which might typically be expected to lead to an increase in enzyme efficiency, has been somewhat relieved by the presence of $\mathrm{APH}\left(2^{\prime \prime}\right)-\mathrm{la}$, which is a highly efficient enzyme capable by itself of protecting bacteria against the 4,6-disubstituted antibiotics.

\section{Fortimicin binding to $A A C\left(6^{\prime}\right)$-Im and $A A C\left(6^{\prime}\right)$-le}

The AAC $\left(6^{\prime}\right)$-Im acetyltransferase shows elevated MICs for almost all aminoglycoside substrates compared to $A A C\left(6^{\prime}\right)-l e$, except in the case of the atypical substrate fortimicin (Table 1). Contrary to what is observed with 4,6disubstituted aminoglycosides, $A A C\left(6^{\prime}\right)$-le elevates resistance to this antibiotic 32-fold above the background level. Although fortimicin comprises only two rings, a decorated aminocyclitol and a single glycan group, it does possess an amino group at the $6^{\prime}$ position which would be the potential site of acetylation by the $A A C\left(6^{\prime}\right)$ enzymes (Figure S1). Since no structural information is available for this aminoglycoside bound to any $\mathrm{AAC}\left(6^{\prime}\right)$ enzyme, we undertook ligand docking studies using the program ICM-Pro. Both kanamycin and fortimicin were docked to receptor models derived from $\mathrm{AAC}\left(6^{\prime}\right)$-Im, $\mathrm{AAC}\left(6^{\prime}\right)$-Ib and $\mathrm{AAC}\left(6^{\prime}\right)$-le. Kanamycin $A$ was used as a test of the docking procedures. This substrate was docked 15 independent times to the three models and in the majority of docking runs (>10/15), poses identical or substantially similar to the known crystal structures were obtained (data not shown).

When fortimicin was docked in 15 independent runs to the $A A C\left(6^{\prime}\right)$-le model, a significant number (7/15) of selfconsistent poses which placed the $\mathrm{N}^{\prime}$ amino group within $0.5 \AA$ of the $N 6^{\prime}$ atom of the crystal structure of the bound kanamycin were observed. In all seven poses, the N6' atom was within $3 \AA$ of the acetyl carbon of the modeled acetyl$\mathrm{CoA}$, and in an orientation relative to the acetyl carbon which could lead to efficient acetyl transfer. Conversely, when fortimicin was docked to $A A C\left(6^{\prime}\right)-\mathrm{Im}$ in 15 independent runs, all of the poses obtained were randomly distributed throughout the binding site, and none of the poses were self-consistent (data not shown). Moreover, none of the poses appeared to be productive, in that there were no cases where the fortimicin $\mathrm{NG}^{\prime}$ atom came close enough to the acetyl carbon of the modeled acetyl-CoA, or in the correct orientation, to facilitate efficient acetylation of the amino group. These docking results are entirely consistent with the differences in the MICs observed for $\operatorname{AAC}\left(6^{\prime}\right)$-Im and $\operatorname{AAC}\left(6^{\prime}\right)$-le. Given that a large number of clearly viable poses were observed for $A A C\left(6^{\prime}\right)$-le, these docking results could explain the differences in resistance to fortimicin produced by these related acetyltransferases.

\section{MATERIALS AND METHODS}

\section{Enzyme cloning and antibiotic susceptibility profile analysis}

The genes for the $A A C\left(6^{\prime}\right)-\operatorname{Im}$ and $A A C\left(6^{\prime}\right)$-le were cloned into the vector pBluescript II KS(+) under the same promoter to minimize potential differences in enzyme expression levels. For $A A C\left(6^{\prime}\right)$-le we generated two constructs by cloning the gene encoding either the first 197 or 179 amino acids of the bifunctional enzyme. Both constructs produced similar MICs when expressed in Escherichia coli JM83 and the construct encoding the 179 amino acid enzyme was used for MIC testing and protein purification. The MICs of various aminoglycoside antibiotics were determined by the broth microdilution tech- 
nique according to the guidelines of the Clinical and Laboratory Standards Institute [26], with E. coli JM83 without vector as a control (Table 1).

\section{Protein purification and enzyme kinetics}

For large scale protein purification the gene for $A A C\left(6^{\prime}\right)-\operatorname{Im}$ was optimized for expression in $E$. coli, cloned into the $\mathrm{pET} 22 \mathrm{~b}(+)$ expression vector, and the protein was purified as previously described [27]. The AAC $\left(6^{\prime}\right)$-Im acetyltransferase activity towards aminoglycosides was monitored spectrophotometrically using a coupled assay [28]. In this assay acetylCoA serves as the source of the acetyl group. Upon acetylation, released coenzyme $A$ reacts with 4,4'-dithiodipyridine releasing 4-thiopyridone $\left(\epsilon_{324}=+19800 \mathrm{M}^{-1} \mathrm{~cm}^{-1}\right)$, which can be monitored at $324 \mathrm{~nm}$. Assay mixtures contained $100 \mathrm{mM}$

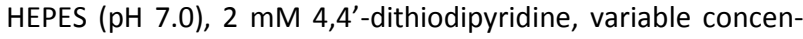
trations of aminoglycoside (1 - $100 \mu \mathrm{M}), 100 \mu \mathrm{M}$ acetyl-CoA, and $2.5-40 \mathrm{mM} \mathrm{MgCl}_{2}$ in a total volume of $250 \mu$ l. Reactions were initiated by the addition of the enzyme and followed at $25^{\circ} \mathrm{C}$. The enzyme's acetyltransferase activity for the respective aminoglycosides was measured from the initial rate of each reaction.

Crystallization, data collection, structure solution and refinement

$A A C\left(6^{\prime}\right)-I m$ was crystallized as previously described [27]. Three different crystal forms were initially obtained, and data collection from form III (an AAC $\left(6^{\prime}\right)$-Im-kanamycin complex in space group $P 6_{5}$ ) has been described [27]. This data was reprocessed to $1.95 \AA$ resolution using XDS [29] and AIMLESS [30] and data are presented in Table S1. A data set to $1.7 \AA$ resolution was collected from a form II apo-AAC $\left(6^{\prime}\right)$-Im crystal at SSRL beamline BL12-2 using X-rays at $12658 \mathrm{eV}$ (0.9795 $\AA$ ). A total of 950 fine phi-sliced (0.2 rotation) images with a 0.2 sec exposure were measured using a Pilatus 6M PAD detector running in shutterless mode. The images were processed using XDS [29], and scaled and merged with AIMLESS [30]. Data collection statistics are also given in Table S1.

The AAC $\left(6^{\prime}\right)-\mathrm{Im}$-kanamycin A structure was solved as described [27] and refined using PHENIX [31], giving a final model comprising 1507 protein atoms, one kanamycin ligand and 83 water molecules, with final $R_{\text {work }}$ and $R_{\text {free }}$ values of $17.05 \%$ and $19.43 \%$ respectively. The apo-AAC $\left(6^{\prime}\right)$-Im structure was solved by molecular replacement using the refined $\mathrm{AAC}\left(6^{\prime}\right)$-Im-kanamycin A structure, with the kanamycin A and water molecules removed. Two independent molecules were found in the asymmetric unit and subsequently refined using PHENIX [31]. The final $R_{\text {work }}$ and $R_{\text {free }}$ values were $18.46 \%$ and 22.93\% respectively (see Table S1 for final statistics for both structures). The atomic coordinates and the structure factors for apo $A A C\left(6^{\prime}\right)-I m$ and the $A A C\left(6^{\prime}\right)-I m$-kanamycin $A$ complex were deposited to the Protein Data Bank with PDB codes 6BFF and $6 \mathrm{BFH}$, respectively.

\section{REFERENCES}

1. Edson RS, Terrell CL (1991). The aminoglycosides. Mayo Clin Proc 66(11): 1158-1164.

\section{Ligand docking}

Ligand docking to $A A C\left(6^{\prime}\right)-\mathrm{Im}, \mathrm{AAC}\left(6^{\prime}\right)-\mathrm{lb}$ and $\mathrm{AAC}\left(6^{\prime}\right)$-le was performed using ICM-Pro 3.8-4 (Molsoft) [32]. The AAC(6')-lb and $\operatorname{AAC}\left(6^{\prime}\right)$-le structures were initially superimposed onto the kanamycin A complex of $\mathrm{AAC}\left(6^{\prime}\right)$-Im. An acetyl-CoA molecule derived from the $A A C\left(6^{\prime}\right)-1 b$-acetyl-CoA-kanamycin $C$ complex (PDB code $1 \mathrm{VOC}$ ) was added to the $\operatorname{AAC}\left(6^{\prime}\right)$-Im and $\operatorname{AAC}\left(6^{\prime}\right)$-le structures to produce composite models, and all other ligands were removed, along with all water molecules. These models were then loaded into ICM-pro and converted to ICM receptor objects, with optimization of hydrogen atom placement. The approximate location of the aminoglycoside binding site was defined using the kanamycin A position observed in AAC $\left(6^{\prime}\right)$ $\mathrm{Im}$, and receptor maps were calculated within ICM-Pro. The aminoglycoside substrates kanamycin and fortimicin were subsequently docked to all three $A A C\left(6^{\prime}\right)$ models. The ligand docking runs were performed multiple times, and the binding modes for the three receptor models with the two substrates were extracted from ICM-Pro ad PDB files.

\section{ACKNOWLEDGMENTS}

This work was supported by the NIH grant R01AI057393 to Sergei B. Vakulenko. Use of the Stanford Synchrotron Radiation Lightsource is supported by the U.S. Department of Energy, Office of Science, Office of Basic Energy Sciences under Contract No. DE-AC02-76SF00515. The SSRL Structural Molecular Biology Program is supported by the DOE Office of Biological and Environmental Research, and by the National Institutes of Health, National Institute of General Medical Sciences (including P41GM103393). The contents of this publication are solely the responsibility of the authors and do not necessarily represent the official views of NIGMS or NIH.

\section{SUPPLEMENTAL MATERIAL}

All supplemental data for this article are available online at www.microbialcell.com.

\section{CONFLICT OF INTEREST}

The authors declare no conflict of interest.

\section{COPYRIGHT}

(C) 2017 Smith et al. This is an open-access article released under the terms of the Creative Commons Attribution (CC BY) license, which allows the unrestricted use, distribution, and reproduction in any medium, provided the original author and source are acknowledged.

Please cite this article as: Clyde A. Smith, Monolekha Bhattacharya, Marta Toth, Nichole K. Stewart, and Sergei B. Vakulenko (2017). Aminoglycoside resistance profile and structural architecture of the aminoglycoside acetyltransferase $\mathrm{AAC}\left(6^{\prime}\right)-\mathrm{Im}$. Microbial Cell 4(12): 402-410. doi: 10.15698/mic2017.12.602

2. Carter AP, Clemons WM, Brodersen DE, Morgan-Warren RJ, Wimberly BT, Ramakrishnan V (2000). Functional insights from the structure of the $30 \mathrm{~S}$ ribosomal subunit and its interactions with antibiotics. Nature 407(6802): 340-348. 
3. Davies JE (1991). Aminoglycoside-aminocyclitol antibiotics and their modifying enzymes. In: Lorian V, editor. Antibiotics in Laboratory Medicine. Williams \& Wilkins, Baltimore; pp 691-713.

4. Vakulenko SB, Mobashery S (2003). Versatility of Aminoglycosides and Prospects for Their Future. Clin Microbiol Reviews 16(3): 430450

5. Davies J, Wright GD (1997). Bacterial resistance to aminoglycoside antibiotics. Trends Microbiol 5(6): 234-240.

6. Shaw KJ, Rather PN, Hare RS, Miller GH (1993). Molecular genetics of aminoglycoside resistance genes and familial relationships of the aminoglycoside-modifying enzymes. Microbiol Rev 57(1): 138-163. PMID: 8385262

7. Smith CA, Baker EN (2002). Aminoglycoside antibiotic resistance by enzymatic deactivation. Curr Drug Targets Infect Dis 2(2): 143-160. PMID:12462145

8. Ramirez MS, Tolmasky ME (2010). Aminoglycoside modifying enzymes. Drug Resist Updat 13:151-171.

9. Doi Y, Arakawa Y (2007). 16S ribosomal RNA methylation: Emerging resistance mechanism against aminoglycosides. Clin Infect Dis 45(1): 88-94.

10. Caldwell SJ, Berghuis AM (2012). Small-angle X-ray scattering analysis of the bifunctional antibiotic resistance enzyme aminoglycoside $\left(6^{\prime}\right)$ acetyltransferase-le/aminoglycoside $\left(2^{\prime \prime}\right)$ phosphotransferasela reveals a rigid solution structure. Antimicrob Agents Chemother 56(4): 1899-1906.

11. Zhang W, Fisher JF, Mobashery S (2009). The bifunctional enzymes of antibiotic resistance. Curr Opin Microbiol 12(5): 505-511.

12. Smith CA, Toth M, Weiss TM, Frase H, Vakulenko SB (2014). Structure of the bifunctional aminoglycoside-resistance enzyme $A A C\left(6^{\prime}\right)$-le$\mathrm{APH}(2 ")$-la revealed by crystallographic and small-angle X-ray scattering analysis. Acta Crystallogr D70(10): 2754-2764.

13. Toth M, Frase H, Antunes NT, Vakulenko SB (2013). Novel aminoglycoside 2"-phosphotransferase identified in a gram-negative pathogen. Antimicrob Agents Chemother 57(1): 452-457.

14. Chow JW, Kak V, You I, Kao SJ, Petrin J, Clewell DB, Lerner SA, Miller GH, Shaw KJ (2001). Aminoglycoside resistance genes aph(2")-lb and $\mathrm{aac}\left(6^{\prime}\right)-\mathrm{Im}$ detected together in strains of both Escherichia coli and Enterococcus faecium. Antimicrob Agents Chemother 45(10): 2691-2694.

15. Shmara A, Weinsetel N, Dery KJ, Chavideh R, Tolmasky ME (2001). Systematic Analysis of a Conserved Region of the Aminoglycoside 6'$\mathrm{N}$-Acetyltransferase Type Ib Antimicrob Agents Chemother 45(12): 3287-3292.

16. Stogios PJ, Kuhn ML, Evdokimova E, Law M, Courvalin P, Savchenko A (2017). Structural and biochemical characterization of Acinetobacter spp. aminoglycoside acetyltransferases highlights functional and evolutionary variation among antibiotic resistance enzymes. ACS Infect Dis 3(2): 132-143.

17. Daigle DM, Hughes DW, Wright GD (1999). Prodigious substrate specificity of $\mathrm{AAC}\left(6^{\prime}\right)-\mathrm{APH}\left(2^{\prime \prime}\right)$, an aminoglycoside antibiotic resistance determinant in enterococci and staphylococci. Chem Biol 6(2): 99-110.

18. Doi Y, Wachino J, Yamane K, Shibata N, Yagi T, Shibayama K, Kato $H$, Arakawa $Y$ (2004). Spread of novel aminoglycoside resistance gene aac(6')-lad among Acinetobacter clinical isolates in Japan. Antimicrob Agents Chemother 48(6): 2075-2080.
19. Sekiguchi J, Asagi T, Miyoshi-Akiyama T, Fujino T, Kobayashi I, Morita K, Kikuchi Y, Kuratsuji T, Kirikae T (2005). Multidrug-resistant Pseudomonas aeruginosa strain that caused an outbreak in a neurosurgery ward and its aac(6')-lae gene cassette encoding a novel aminoglycoside acetyltransferase. Antimicrob Agents Chemother 49(9): 3734-3742.

20. Wright GD, Ladak P (1997). Overexpression and characterization of the chromosomal aminoglycoside 6'-N-acetyltransferase from Enterococcus faecium. Antimicrob Agents Chemother 41(5): 956-960.

21. Zhu CB, Sunada A, Ishikawa J, Ikeda Y, Kondo S, Hotta K (1999). Role of aminoglycoside 6 '-acetyltransferase in a novel multiple aminoglycoside resistance of an actinomycete strain \#8: Inactivation of aminoglycosides with 6'-amino group except arbekacin and neomycin. J Antibiot (Tokyo) 52(10): 889-894.

22. Vetting MW, Park CH, Hegde SS, Jacoby GA, Hooper DC, Blanchard JS (2008). Mechanistic and structural analysis of aminoglycoside $\mathrm{N}$ acetyltransferase $A A C\left(6^{\prime}\right)-l b$ and its bifunctional, fluoroquinoloneactive AAC(6')-lb-cr variant. Biochemistry 47(37): 9825-9835.

23. Maurice F, Broutin I, Podglajen I, Benas P, Collatz E, Dardel F (2008). Enzyme structural plasticity and the emergence of broadspectrum antibiotic resistance. EMBO Rep 9(4): 344-349.

24. Wybenga-Groot LE, Draker KA, Wright GD, Berghuis AM (1999). Crystal structure of an aminoglycoside 6'-N-acetyltransferase: defining the GCN5-related N-acetyltransferase superfamily fold. Structure 7(5): 497-507.

25. Vetting MW, Magnet S, Nieves E, Roderick SL, Blanchard JS (2004). A bacterial acetyltransferase capable of regioselective $\mathrm{N}$-acetylation of antibiotics and histones. Chem Biol 11(4): 565-573.

26. Clinical and Laboratory Standards Institute (2009). Methods for dilution antimicrobial susceptibility tests for bacteria that grow aerobically; Approved standard. In: CLSI document M07-A8. Clinical and Laboratory Standards Institute, Wayne, PA, USA.

27. Toth M, Vakulenko SB, Smith CA (2012). Purification, crystallization and preliminary $\mathrm{X}$-ray analysis of the aminoglycoside-6'acetyltransferase AAC(6')-Im. Acta Crystallogr F68(4): 472-475.

28. Williams JW, Northrop DB (1978). Kinetic mechanisms of gentamicin acetyltransferase I. Antibiotic-dependent shift from rapid to nonrapid equilibrium random mechanisms. J Biol Chem 253(17): 59025907. PMID: 681327

29. Kabsch W (2010). Integration, scaling, space-group assignment and post-refinement. Acta Crystallogr D66(2): 133-144.

30. Evans PR, Murshudov GN (2013). How good are my data and what is the resolution? Acta Crystallogr D69(7): 1204-1214.

31. Adams PD, Afonine PV, Bunkóczi G, Chen VB, Davis IW, Echols N, Headd JJ, Hung LW, Kapral GJ, Grosse-Kunstleve RW, McCoy AJ, Moriarty NW, Oeffner R, Read RJ, Richardson DC, Richardson JS, Terwilliger TC, Zwart PH (2010). PHENIX: A comprehensive Python-based system for macromolecular structure solution. Acta Crystallogr D66(2): 213221.

32. Abagyan RA, Totrov MM, Kuznetsov DA (1994). ICM: A new method for protein modeling and design: Applications to docking and structure prediction from the distorted native conformation. J Comp Chem 15(5): 488-506. 